\title{
Levonorgestrel-releasing intrauterine system vs. endometrial thermal ablation for menorrhagia
}

\author{
Theodoros D. Theodoridis ${ }^{1,2}$, Leonidas Zepiridis ${ }^{1,2}$, Menelaos Zafrakas ${ }^{1}$,

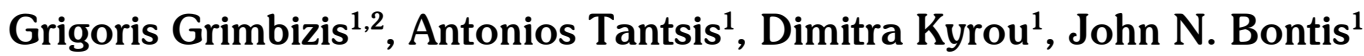 \\ ${ }^{1} 1^{\text {st }}$ Department of Obstetrics \& Gynaecology, Papageorgiou General Hospital, Aristotle University of Thessaloniki, \\ ${ }^{2}$ Gynaecological Endoscopy Unit, Geniki Kliniki, Thessaloniki, Greece
}

\begin{abstract}
OBJECTIVE: To evaluate the efficacy of a Levonorgestrel-releasing Intrauterine System (LNGIUS) in controlling menorrhagia in comparison with endometrial thermal rollerball ablation. DESIGN: Seventy-nine consecutive patients with menorrhagia underwent either LNG-IUS insertion $(n=42)$ or hysteroscopical endometrial thermal rollerball ablation $(n=37)$ in a prospective, observational, comparative study. Women reported duration of uterine bleeding in days prior to, and six and 12 months after each intervention. Prior to each intervention, endometrial, cervical or other pathological conditions of the genital tract were excluded. GnRH analogues for endometrial suppression were given for ten weeks before endometrial ablation but not prior to LNG-IUS insertion. RESULTS: There were no differences in duration of uterine bleeding before each intervention in the two groups. The duration of uterine bleeding was lower in the LNG-IUS group as compared with endometrial ablation at $\operatorname{six}(p<0.001)$ and 12 months $(p<0.001)$ after each intervention. Furthermore, the effect on reduction of bleeding was stronger in the LNG-IUS group as compared with the endometrial ablation group at six $(p<0.001)$ and 12 months $(p<0.001)$. CONCLUSIONS: The LNG-IUS was more efficacious than endometrial thermal ablation in reducing duration of uterine bleeding at six and 12 months post-intervention.
\end{abstract}

Key words: Endometrial thermal rollerball ablation, Levonorgestrel-releasing Intrauterine System (LNG-IUS), Menorrhagia

\section{INTRODUCTION}

Menorrhagia is the commonest cause of iron defi-

\section{Address for correspondence:}

TD Theodoridis, Lecturer in Obstetrics and Gynaecology, $1^{\text {st }}$ Department of Obstetrics \& Gynaecology, Papageorgiou General Hospital, Periferiaki Odos Thessalonikis, N. Efkarpia, 56403, Thessaloniki, Greece, Tel: +30-2310-693131, Fax: +30-2310-992890, e-mail: theodtheo@yahoo.gr Received 25-03-08, Revised 30-09-08, Accepted 20-10-08 ciency anemia in premenopausal women. ${ }^{1}$ Anemia is one of the most widespread and neglected nutritional deficiencies in the world today, predisposing women to ill health and disease. ${ }^{2}$ Menorrhagia is estimated to occur in $30 \%$ of women in their childbearing years. By definition, diagnosis of menorrhagia is made when the duration of bleeding is equal to or greater than six days or blood loss is at least $80 \mathrm{ml}$ and other pathological conditions have been excluded. However, many 
women seek consultation for even milder bleeding episodes, due to the associated stress, discomfort, and quality of life impairment, thus making menorrhagia one of the most frequent reasons for gynaecological consultation. ${ }^{3-5}$

Traditional medical treatment for menorrhagia has been only temporarily effective, if at all, and most patients refuse to be subjected to prolonged administration of medications. Surgical treatment, including hysterectomy and endometrial ablation, is not suitable for women wishing to preserve fertility. Though successful pregnancies have been reported after endometrial ablation, this procedure is generally not recommended for women wishing to retain the option of future pregnancy. ${ }^{3-5}$

The levonorgestrel-releasing intrauterine system (LNG-IUS) has emerged in recent years as a valuable alternative to classical medical and surgical methods of menorrhagia treatment. The system consists of a 32-mm T-shaped polyethylene frame with a reservoir containing $52 \mathrm{mg}$ of Levonorgestrel (LNG), covered by a silicone membrane. ${ }^{6}$ After insertion, the initial release of LNG into the uterine cavity is $20 \mu \mathrm{g} / \mathrm{d}$ and a stable plasma concentration of $150-200 \mathrm{pg} / \mathrm{ml}$ is achieved after the first few weeks. ${ }^{6}$ The plasma concentration of LNG in patients using the LNG-IUS is less than $25 \%$ of that seen with $150 \mu \mathrm{g}$ of oral LNG. ${ }^{6}$ By slowly releasing the progestin LNG into the uterine cavity, the LNG-IUS suppresses endometrial growth, causing atrophy of the endometrial glands, decidualisation of the stroma, thickening of the cervical mucous, and desensitisation of the endometrium to estrogen, which all lead to excellent control of menorrhagia, providing in parallel a highly satisfactory contraceptive action. ${ }^{1}$ In the present study, the efficacy of the LNG-IUS LNG-IUS for menorrhagia control is compared to thermal endometrial ablation.

\section{PATIENTS AND METHODS}

Between January 2001 and December 2006, 79 consecutive patients with menorrhagia underwent either insertion of a LNG-IUS $(n=42)\left(\right.$ Mirena $^{\circledR}$, Schering Health, Berlin, Germany) or hysteroscopical endometrial ablation $(\mathrm{n}=37)$. The study was designed as a prospective, observational, comparative protocol at the $1^{\text {st }}$ Department of Obstetrics and Gynaecology of the Aristotle University of Thessaloniki, Greece. Patients were allocated to either LNG-IUS insertion or endometrial ablation, according to their own preference, after detailed counselling. Informed consent was obtained from each patient prior to each procedure. Data were collected prospectively and analysed in a single blinded fashion.

Prior to LNG-IUS insertion or endometrial ablation, endometrial pathology (endometrial carcinoma and/or endometrial atypical hyperplasia) and cervical pathology (cervical cancer and preinvasive intraepithelial lesions) were excluded by D \& C or endometrial sampling using Pipelle ${ }^{\circledast}$ (Cooper Surgical, Trumbull, Connecticut, USA) and cervical smear, respectively. Transvaginal ultrasonography was used to exclude possible causes of menorrhagia, including myomas and endometrial polyps, as well as adnexal pathology. Women with uterine or adnexal pathology as well as women desiring preservation of fertility were excluded from the study. Women participating in the study reported the duration of uterine bleeding in days prior to, and six and 12 months after each intervention. Ten weeks prior to endometrial ablation, $\mathrm{GnRH}$ analogues (leuprolide, Elityran ${ }^{\circledR}$, Vianex, Athens, Greece) were administered in order to suppress the endometrium and achieve minimal endometrial thickness. There was no such intervention prior to LNG-IUS insertion.

LNG-IUS insertion was performed as an office procedure one day after cessation of menstrual bleeding. All women had a negative urine pregnancy test prior to LNG-IUS insertion. The uterine cavity length was measured using uterine sounding, followed by LNG-IUS insertion. Accurate LNG-IUS position was documented with transvaginal ultrasonography immediately after insertion. There was no need for cervical dilatation, general or local anesthesia, analgesics or antibiotics.

The rollerball method was used for endometrial ablation. In brief, after gradual dilatation of the uterine cervix (Hegar size up to 10.5) and uterine sounding in order to measure the length of the uterine cavity, a 26 F operative hysteroscope was inserted (Storz Company, Tuttlingen, Germany). The uterine cavity was distended using isotonic solution (Purisole ${ }^{\circledR}$, Fresenius Kabi, Bad Homburg, Germany). The internal ostia of 
the saplings were identified and the corresponding endometrium was ablated first, followed by successive ablation of the endometrium of the fundus and the anterior and posterior uterine wall. Fluid balance was checked throughout the procedure. Endometrial thermal ablation was performed as an outpatient procedure, under general or epidural anesthesia, with a mean duration of 15-40 minutes and a maximum of a 3-hour postoperative hospital stay. Medications used postoperatively included mild analgesics (diclofenac sodium $100 \mathrm{mg}$ PR) and antibiotics (1.5g Cefuroxime intra-operatively), when appropriate.

Statistical analysis was carried out using the SPSS for Windows, version 16 (SPSS Inc., Chicago, IL, USA). The Kolmogorov-Smirnov test was used to check normality assumptions. The independent samples t-test was used to check for significant differences between continuous variables. A repeated measures ANOVA was conducted to check for differences between treatment methods in a longitudinal setting. P-values less than 0.05 were considered statistically significant.

\section{RESULTS}

Data regarding age, parity, and history of previous cesarean section is presented in Table 1. Forty-two patients were allocated to LNG-IUS insertion and 37 to endometrial thermal rollerball ablation; the mean $\pm(\mathrm{SD})$ age in each group was $37.3( \pm 5.8)$ and $42.8( \pm 3.4)$ years, respectively. Mean parity was 1.7 $( \pm 0.9)$ in the LNG-IUS group and $1.9( \pm 0.8)$ in the endometrial ablation group. In the LNG-IUS group, $47.6 \%(n=20)$ had a history of at least one previous cesarean section, while in the endometrial ablation group this rate was $48.6 \%(n=18)$

An overview of comparisons between the LNG-

Table 1. Age, parity, and history of previous cesarean section in the two interventional groups at entrance to the study

\begin{tabular}{lcc}
\hline & \multicolumn{2}{c}{ Patient group } \\
\cline { 2 - 3 } Patient variable & LNG-IUS $(\mathbf{n}=\mathbf{4 2})$ & Ablation $(\mathbf{n}=\mathbf{3 7})$ \\
\hline Mean Age (years) \pm SD & $37.3 \pm 5.8$ & $42.8 \pm 3.4$ \\
Mean Parity ( \pm SD) & $1.7 \pm 0.9$ & $1.9 \pm 0.8$ \\
Cesarean section rate & $47.6 \%(\mathrm{n}=20)$ & $48.6 \%(\mathrm{n}=18)$ \\
\hline
\end{tabular}

IUS and the endometrial ablation group regarding the duration of bleeding prior to, and six and 12 months after each intervention, as well as the reduction in the duration of bleeding six and 12 months after each procedure, is presented in Table 2 and Figure 1 . There were suggestive but not statistically significant differences in duration of uterine bleeding between users of LNG-IUS and the endometrial ablation group prior to each intervention $(p=0.064)$. In contrast, the duration of uterine bleeding after each procedure was significantly lower in the LNG-IUS

Table 2. Duration of bleeding in the two groups prior to and at six and 12 months after each intervention

\begin{tabular}{lccc}
\hline & \multicolumn{3}{c}{ Patient group } \\
\cline { 2 - 4 } Uterine bleeding* & $\begin{array}{c}\text { LNG-IUS } \\
(\mathbf{n = 4 2})\end{array}$ & $\begin{array}{c}\text { Ablation } \\
(\mathbf{n}=37)\end{array}$ & p-values ** \\
\hline Prior to intervention & 6.8 & 7.2 & 0.064 \\
Six months later & 2.7 & 4.4 & $<.001$ \\
Twelve months later & 2.2 & 4.2 & $<.001$ \\
Reduction at six months & 4.0 & 2.8 & $<.001$ \\
Reduction at 12 months & 4.5 & 3.0 & $<.001$ \\
\hline
\end{tabular}

*in days, **2 independent samples t-test

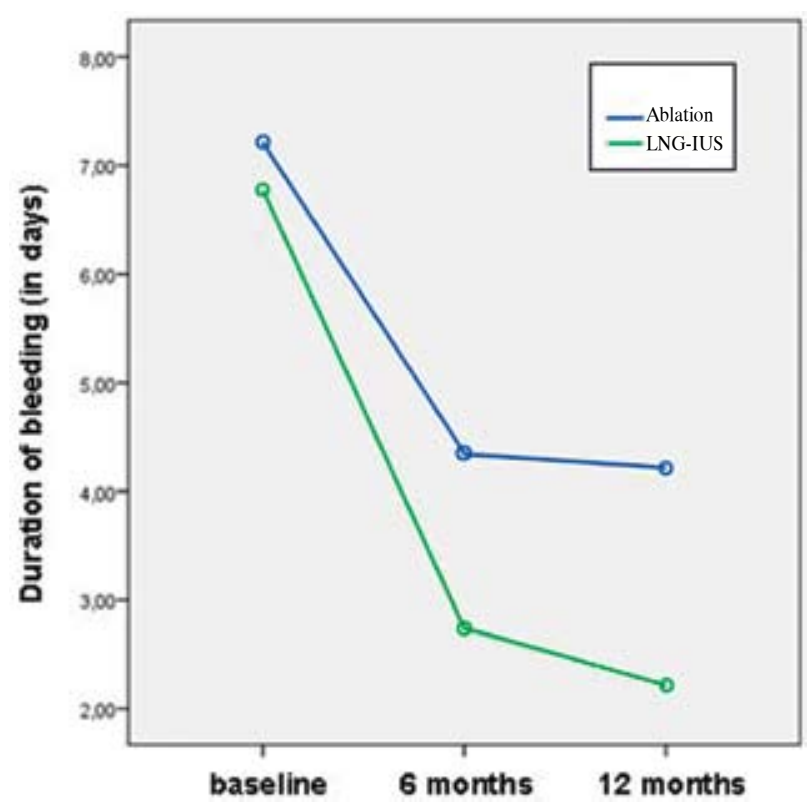

Figure 1. Comparisons between the Levonorgestrel-releasing Intrauterine System (LNG-IUS) and the endometrial ablation group regarding the duration of bleeding prior to (at baseline), six, and 12 months after each intervention. 
group as compared with endometrial ablation at six $(\mathrm{p}<0.001)$ and 12 months $(\mathrm{p}<0.001)$ after intervention. Though mean age differed significantly in the two groups $(\mathrm{p}<0.001)$, age was not a significant covariate $(p=0.305)$. Furthermore, the effect on reduction in the days of bleeding was stronger in the LNG-IUS as compared with the endometrial ablation group at six $(\mathrm{p}<0.001)$ and 12 months $(\mathrm{p}<0.001)$. Age did not affect this reduction $(\mathrm{p}=0.455)$.

\section{DISCUSSION}

Effectiveness of medical treatment for menorrhagia is usually temporary, while surgical options are generally incompatible with preservation of fertility, with potentially avoidable morbidity, or even mortality, and high cost. Thus, the LNG-IUS appears to be an attractive alternative to these methods. In the present study, the efficacy of the LNG-IUS has been compared with thermal endometrial ablation, the least invasive surgical procedure for menorrhagia control. Follow-up of patients at six and 12 months after each intervention showed that duration of bleeding was significantly reduced at both intervals in patients who received LNG-IUS as compared with those who underwent thermal endometrial ablation.

Previously published studies comparing the efficacy of LNG-IUS with endometrial ablation in controlling menorrhagia have led overall to inconclusive results. In a recent randomised study $(n=44)$, Tam et al reported a better health status at one-year follow-up for patients who underwent thermal balloon endometrial ablation as compared with patients who received LNG-IUS treatment. ${ }^{7}$ Consistently, Soysal et al., in a randomised study of 72 patients, found that at one-year follow-up, LNG-IUS was effective but of lower efficacy compared to thermal balloon ablation in reducing menstrual blood loss. "Somewhat less satisfactory results" with LNG-IUS as compared with endometrial resection at one-year follow-up have been reported in a prospective, open, controlled trial $(n=70) .{ }^{9}$ In contrast, in a recent prospective randomised study of 79 women, Busfield et al. found that at 12 and 24 months of follow-up, women with heavy menstrual bleeding treated with the LNG-IUS had significantly lower bleeding (measured as pictorial bleeding assessment chart scores) than women treated with thermal balloon ablation. ${ }^{10}$ Five other studies, however, did not show significant differences between LNG-IUS and various methods of endometrial ablation. ${ }^{11-15}$ Differences in study design, low statistical power due to objective difficulties in recruitment of patients, and different methods of endometrial ablation used can explain these heterogeneous results. Larger studies comparing LNG-IUS with widely applied endometrial ablation methods, as well as second and third generation ablative procedures, could clarify this issue.

Nevertheless, the LNG-IUS insertion has several advantages over thermal endometrial ablation: it can be performed as an office procedure, whereas thermal ablation is a hospital outpatient procedure; LNGIUS insertion is non-operative and hence virtually devoid of operative complications, such as excessive trauma and bleeding; there is no need for anesthesia, cervical dilatation, and antibiotics; and for the most it does not preclude future fertility. Furthermore, in cost-effectiveness analysis LNG-IUS appears to be more advantageous as compared with endometrial ablation. ${ }^{16,17}$ The main limitation of endometrial thermal ablation is the fact that it can be used only in parous women or women who do not wish to get pregnant. On the other hand, LNG-IUS insertion is the treatment of choice in patients with menorrhagia wishing to preserve fertility. Thus, LNG-IUS insertion appears to be the medical treatment of choice in women suffering from menorrhagia.

Discosure: The authors declare that they do not have any conflict(s) of interest.

\section{REFERENCES}

1. Radesic B, Sharma A, 2004 Levonorgestrel-releasing intrauterine system for treating menstrual disorders: A patient satisfaction questionnaire. Aust NZ J Obstet Gynecol 44: 247-251.

2. Wildemeersch D, Rowe PJ, 2005 Assessment of menstrual blood loss in Belgian users of a new T-shaped levonorgestrel-releasing intrauterine system. Contraception 71 : 470-473.

3. Stewart A, Cummins C, Gold L, Jordan R, Phillips W, 2001 The effectiveness of the levonorgestrel-releasing intrauterine system in menorrhagia: a systematic review. Br J Obstet Gynaecol 108: 74-86.

4. Chimbira TH, Anderson AB, Turnbull AC, 1980 Relation 
between measured menstrual blood loss and patient's subjective measurement of loss, duration of bleeding, number of sanitary towels used, uterine weight and endometrial surface area. Br J Obstet Gynaecol 87: 603-609.

5. Monteiro I, Bahamondes L, Diaz J, Perrotti M, Petta C, 2002 Therapeutic use of levonorgestrel-releasing intrauterine system in women with menorrhagia: a pilot study. Contraception 65: 325-328.

6. American College of Obstetricians and Gynecologists Committee on Gynecologic Practice, 2006 ACOG committee opinion. No. 337: Noncontraceptive uses of the levonorgestrel intrauterine system. Obstet Gynecol 107: 1479-1482.

7. Tam WH, Yuen PM, Shan Ng DP, Leung PL, Lok IH, Rogers MS, 2006 Health status function after treatment with thermal balloon endometrial ablation and levonorgestrel intrauterine system for idiopathic menorrhagia: a randomized study. Gynecol Obstet Invest 62: 84-88.

8. Soysal M, Soysal S, Ozer S, 2002 A randomized controlled trial of levonorgestrel releasing IUD and thermal balloon ablation in the treatment of menorrhagia. Zentralbl Gynakol 124: 213-219.

9. Crosignani PG, Vercellini P, Mosconi P, Oldani S, Cortesi I, De Giorgi O, 1997 evonorgestrel-releasing intrauterine device versus hysteroscopic endometrial resection in the treatment of dysfunctional uterine bleeding. Obstet Gynecol 90: 257-263.

10. Busfield RA, Farquhar CM, Sowter MC, et al, 2006 A randomised trial comparing the levonorgestrel intrauterine system and thermal balloon ablation for heavy menstrual bleeding. BJOG 113: 257-263.

11. Rauramo I, Elo I, Istre O, 2004 Long-term treatment of menorrhagia with levonorgestrel intrauterine system versus endometrial resection. Obstet Gynecol 104: 13141321.

12. Istre O, Trolle B, 2001 Treatment of menorrhagia with the levonorgestrel intrauterine system versus endometrial resection. Fertil Steril 76: 304-309.

13. Barrington JW, Arunkalaivanan AS, Abdel-Fattah M, 2003 Comparison between the levonorgestrel intrauterine system (LNG-IUS) and thermal balloon ablation in the treatment of menorrhagia. Eur J Obstet Gynecol Reprod Biol 108: 72-74.

14. Henshaw R, Coyle C, Low S, Barry C, 2002 A retrospective cohort study comparing microwave endometrial ablation with levonorgestrel-releasing intrauterine device in the management of heavy menstrual bleeding. Aust N Z J Obstet Gynaecol 42: 205-209.

15. Romer T, 2000 Prospective comparison study of levonorgestrel IUD versus Roller-Ball endometrial ablation in the management of refractory recurrent hypermenorrhea. Eur J Obstet Gynecol Reprod Biol 90: 27-29.

16. Brown PM, Farquhar CM, Lethaby A, Sadler LC, Johnson NP, 2006 Cost-effectiveness analysis of levonorgestrel intrauterine system and thermal balloon ablation for heavy menstrual bleeding. BJOG 113: 797-803.

17. You JH, Sahota DS, MoYuen P, 2006 A cost-utility analysis of hysterectomy, endometrial resection and ablation and medical therapy for menorrhagia. Hum Reprod 21: 1878-1883. 